\title{
Net losses
}

\section{Overfishing in the north Atlantic Ocean has left fish stocks in peril.}

In a Perfect Ocean

by Daniel Pauly \& Jay Maclean

Island Press: 2003. 175 pp. \$50, 238.50 (hbk); $\$ 26, \mathfrak{E} 19.50$ ( $p b k$ )

\section{John Shepherd}

Daniel Pauly is a pioneer of bold new methods for the assessment of marine ecosystems. His methods for estimating natural mortality rates, for interpreting lengthfrequency distributions and for quantifying energy pathways in marine food webs were all highly controversial when they were introduced, but are now accepted as providing useful rough and ready approximations to reality. In this new book, Pauly and co-author Jay Maclean report the results of another, even bolder, venture: an attempt to undertake a holistic assessment of the state of fisheries and ecosystems in the whole of the north Atlantic Ocean.

This work has been carried out as part of the "Sea Around Us Project" (see www.saup.fisheries.ubc.ca), a programme based at the University of British Columbia that involves an international team of researchers and reviewers. In a Perfect Ocean provides an account of this work for a general audience, to supplement several publications in the professional literature. It includes a good historical review of the marine resources (especially the fish stocks) of the north Atlantic, but the centrepiece is the analysis of their decline as a result of exploitation, mostly during the twentieth century.

Pauly and his team have used his Ecopath with Ecosim software (www.ecopath.org) to quantify food webs and trophic pyramids, along with some statistical extrapolations to areas where the data are inadequate, to create an overview for the whole ocean basin. This will probably be controversial, but my overall impression is that they are unlikely to be far wrong. After all, much of the story, for such areas as the Grand Banks off Newfoundland and the North Sea, is already well documented and depressingly familiar.

The essence of their story is contained in two striking series of maps (figures 8 and 14), which show the spatial distributions of the rise in fishing intensity and the decline of fish biomass from 1900 to 1999 . We have known for years that fishing intensity (expressed as a catch/biomass ratio) has been close to 1.0 in many of the most productive areas for several decades. Pauly and Maclean's holistic view now reveals a resultant decline of biomass, by a factor of ten or more, in those same areas. Similar estimates have been available for selected stocks for many years through international organizations such

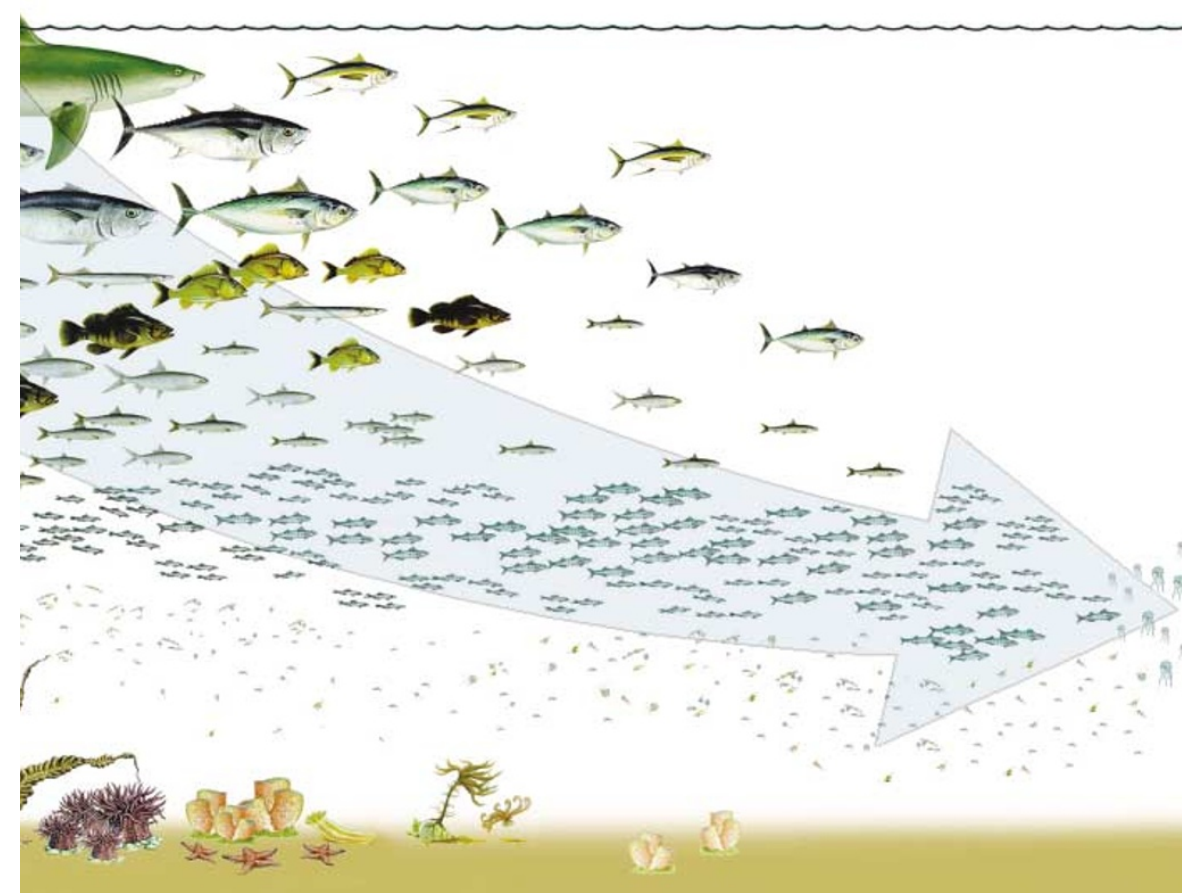

Fishing down the food web: when large fish are gone, small ones further down the food web are caught.

as the International Council for the Exploration of the Sea (www.ices.dk) and the Northwest Atlantic Fisheries Organization (www.nafo.ca). But these estimates were not taken too seriously even by the scientists whose models produced them, because they might have taken insufficient account of associated changes in predator and prey abundances, and thus in natural mortality and growth rates. However, recent work based on an analysis of historical survey data (reported by R. A. Myers and B. Worm, Nature 423, 280-283; 2003) provides strong support for their credibility.

This analysis by Pauly and colleagues, which specifically includes the effects of interactions in the trophic web, provides further support for the reality of massive declines of heavily exploited fish stocks. We can no longer comfort ourselves with the belief that nature will readjust and ameliorate the adverse effects that we have wrought.

The book contains much else of interest, including a good account of how we got into this mess, and a much less satisfactory chapter on what to do about it. Like everyone else, the authors conclude that substantial reductions in fishing effort are required, but they have little to add to the existing portfolio of tools (catch quotas, closed areas and vessel buy-back schemes) for achieving this.

In their preface, Pauly and Maclean remark that the scientific advice on managing sustainable fisheries has mostly gone unheeded. Indeed it has, and the reason for this is simple: all effective conservation measures require that fewer fish be killed, and that means (in the short term) that fishermen's incomes will be reduced. This creates a fundamental conflict between short-term losses and long-term gains that has not yet been resolved anywhere in the world. Unless and until we can find a way to reconcile these, we must expect fishermen and their representatives to oppose with vigour anything that might actually work.

One possible way forward could be the use of short-term transitional aid, such as an effort buy-back scheme (to be regarded as an investment in a better future) that could be paid for in the long term by substantial resource rental charges. However, Pauly and Maclean do not really address the powerful economic forces that have prevented progress for so long, nor possible ways in which the system might be engineered to make them less destructive. This is a matter of regret, because most of the methods they discuss have already been tried, and have not yet solved the problem.

In particular, they suggest a carbon tax (affecting fuel costs) as a potential solution. But on their own figures for tons of fuel used to catch tons of fish, a carbon tax of about US\$50 per ton of fuel is unlikely to affect the behaviour of fishermen very much, if it allows them to land fish worth approximately $\$ 5,000$. Something 
more subtle and effective is needed.

Overall, this book is a useful contribution to the literature, and one can hardly disagree with the conclusion that overfishing is "a primary cause of ecosystem disruption". It has some excellent images; in particular figure 17 (shown overleaf), which is a graphic illustration of what it means to fish down the food web, and deserves to be widely reproduced. But I found the book's structure awkward: it has no less than 30 pages of prefaces, and another 30 pages of endnotes, including some substantial discussions of important issues (such as whaling and international institutions), running to several pages each.

Those who work in the field will find that the book is a bold attempt to create an ocean-wide overview that complements the more conventional stock-by-stock reductionist methods. General readers will find a broad, and in places passionate, account of the state of a whole ocean and its resources that is both accurate and informative. One can only hope that it will help to motivate more strenuous and effective efforts to deal with the problems so clearly identified, which is, I am sure, what its authors intend.

John Shepherd is at the Southampton

Oceanography Centre, Empress Dock,

University of Southampton,

Southampton SO14 3ZH, UK.

\section{More on fisheries}

Handbook of Fish Biology and

Fisheries, Vols 1 and 2

edited by Paul J. B. Hart \& John D. Reynolds Blackwell, $£ 130$

\section{New in paperback}

\author{
I Have Landed \\ Stephen Jay Gould \\ Vintage, $£ 7.99$
}

\section{The Constants of Nature \\ by John Barrow \\ Vintage, $£ 8.00$}

"Barrow discusses the role of constants of nature, the historical quest to understand them, the role of the anthropic principle as a guiding philosophy and some recent evidence suggesting that some of the constants of nature are probably not constants at all." Thanu Padmanabhan Nature 419, 780 (2002).

\section{The Borderlands of Science: Where Sense} Meets Nonsense

by Michael Shermer

Oxford University Press, £9.99

The Way of the Cell: Molecules, Organisms and the Order of Life

by Harold M. Franklin

Oxford University Press, £12.95

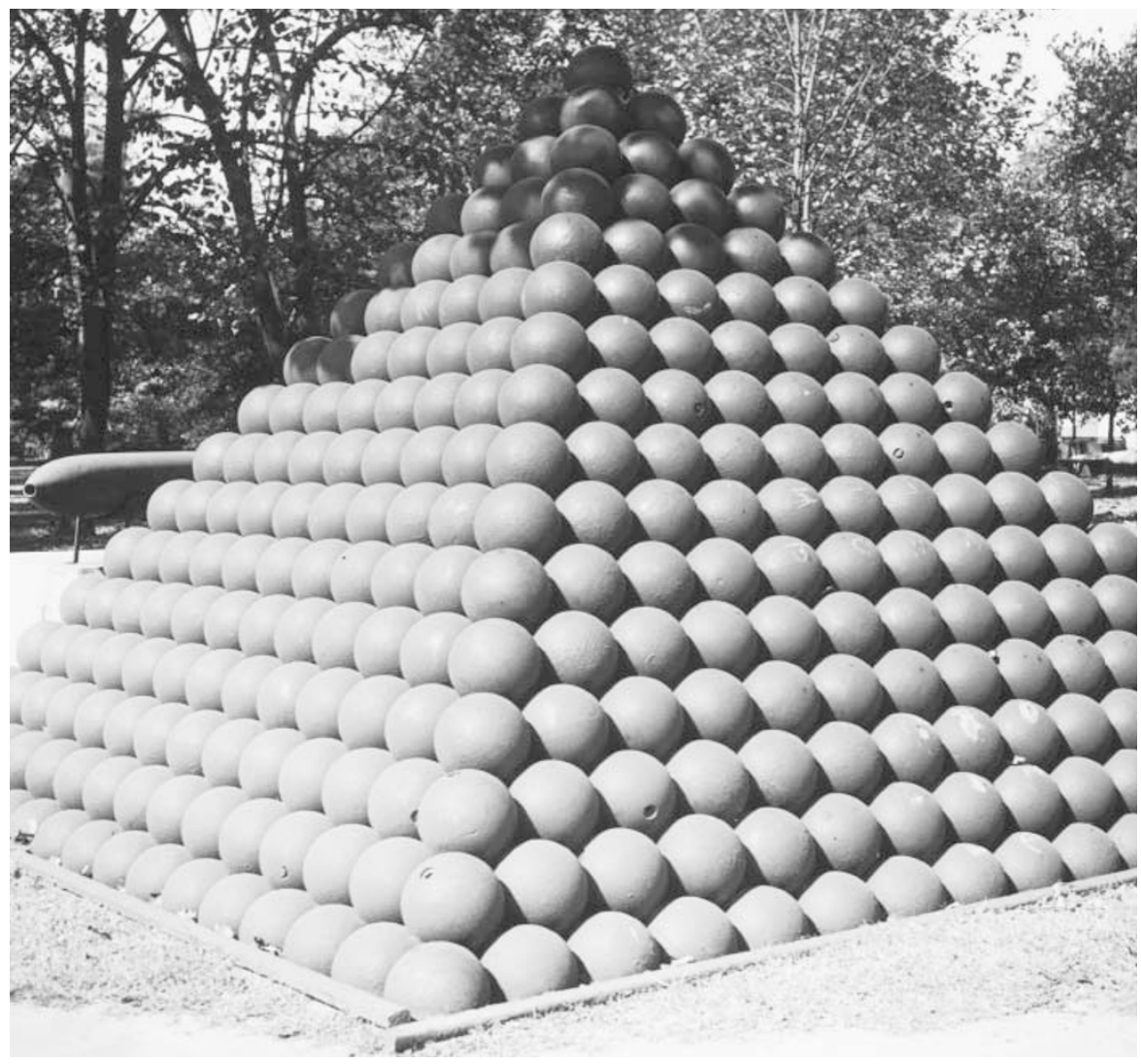

Packing them in: cannon balls stored in a pyramid are stacked together as densely as possible.

• The proof of
the packing

\section{Kepler's Conjecture: How Some of the Greatest Minds in History Helped Solve One of the Oldest Math Problems in the World by George G. Szpiro}

Wiley: 2003. 304 pp. $118.50, \$ 24.95$, €24.95

\section{Neil Sloane}

The classical sphere-packing problem is to determine how densely a large number of identical spheres (such as ball-bearings) can be packed together in a finite space. In 1611 the German astronomer Johannes Kepler stated that no packing could be denser than that of the face-centred cubic (f.c.c.) lattice arrangement favoured by grocers for stacking oranges, which fills about 0.7405 of the available space. It took mathematicians some 400 years to prove him right.

Kepler's Conjecture gives an entertaining and readable account of the history of the problem and the attempts to solve it, culminating with Thomas Hales' successful proof, announced in 1998. George Szpiro also discusses a large number of peripherally related topics, including David Hilbert's list of 23 unsolved mathematical problems from 1900 (Kepler's conjecture is part of problem 18), the kissing-number problem (how many balls can touch another ball of the same size), linear programming and Lord Kelvin's soapfilm problem.

The book is a mixture of mathematics, history and anecdotes. In his research, the author has found many good stories to retell. Even people familiar with the subject will find new anecdotes here, and it seems that most of them are more-or-less true, although one might quibble with the details. Did John Conway's father really teach chemistry to two of the Beatles? Well, sort of.

The tone of the remarks is sometimes derisive, which some readers may find offensive rather than humorous. Young Carl Friedrich Gauss is described as a "little squirt", 'wrangler' is "one of those esoteric blue-ribbon signs of esteem... reserved for British overachievers", and sheaf theory is a "major bore". And after a rather harsh discussion of the attempts of the great Hungarian geometer László Fejes Tóth (his name is consistently misspelled in the book) to prove the dodecahedral conjecture, Szpiro writes: "One might come away from this chapter with the impression that Fejes-Tóth was a bumbling dreamer whose work mostly contained unfulfilled promises and unproven hypotheses. This does not represent the whole picture." Indeed not.

The mathematical content is less satisfactory than the historical part. As William Barlow described in Nature in 1883 (29, 186-188), the f.c.c. packing can be built up by layers. Put down a layer of spheres arranged in a triangular lattice - the arrangement used 